\title{
Concentração regional do valor bruto de produção da banana do Paraná, Brasil (1995 a 2010)
}

\author{
Regional concentration of banana production gross value in Paraná, Brazil (1995-2010)
}

\author{
Luiz Moreira Coelho Junior ${ }^{\mathrm{I}}$
}

RESUMO

Este estudo analisou o grau de concentração do valor bruto da produção de banana no estado do Paraná, no período 1995-2010. Os dados utilizados estão disponíveis no Instituto Paranaense de Desenvolvimento Econômico e Social. O grau de concentração foi determinado por meio da Razão de Concentração, do Índice de Herfindahl-Hirschman e do Índice de Theil. No período estudado, foi observado um crescimento médio anual de 12,92\% a.a. no valor bruto de produção da banana no Paraná; os polos de produção de banana se encontram na Região Metropolitana de Curitiba e a mesorregião do Norte Pioneiro; a razão de concentração municipal foi moderadamente alta a muito alta e, em nível microrregional, foi ainda mais concentrada; o índice de Herfindahl-Hirschman apresentou concentração com grandezas similares nos níveis mesorregional e microrregional. Enquanto indicador, o municipal apontou leve concentração; o índice de Theil mostrou concentração estacionária nos níveis microrregional e municipal e indicou concentração em nível de mesorregião.

Palavras-chave: bananicultura, estudo de mercado, índice de concentração, regionalização.

\section{ABSTRACT}

The degree of concentration of banana production gross value in Paraná State was studied in the 1995-2010 period. The data base is available at IPARDES - Paraná Institute of Economic and Social Development. The degree of concentration was determined by the Concentration Ratio, the HerfindahlHirschman Index and the Theil Index. In the period studied, an average annual growth of $12.92 \%$ in the value of banana production in Paraná was observed; the poles of banana production are the Metropolitan region of Curitiba and the Norte Pioneiro mesoregion. Concentration Ratio was moderately high to very high at municipal level, and even higher at micro-region level; the Herfindahl-Hirschman Index showed similar magnitudes at mesoregional and microregional levels for concentration, while the municipal indicator shows a slight concentration. The Theil index showed stationary concentration levels in the microregional and municipal region and indicated the municipal mesoregion concentration.

Key words: banana crop, market study, concentration ratio, regionalization.

\section{INTRODUÇÃO}

Abanana(Musa sp.)éuma importante fonte de alimento humano, sendo uma das frutas mais consumida no mundo, seja in natura ou processada. A contribuição para que a banana seja a fruta mais comercializada no mundo é pela sua facilidade de propagação e manejo. $\mathrm{O}$ mercado da banana tem relevância econômica e social, principalmente, na região dos trópicos (SOTO, 2012).

Segundo a FAO (2012), a produção mundial em 2009 foi de 97,4 milhões de toneladas, concentrada em países como a Índia $(27,7 \%)$, Filipinas $(9,25 \%)$, China $(9,25 \%)$, Equador $(7,84)$ e Brasil (6,96\%). A área cultivada mundial chegou a 4,9 milhões de hectares e o Brasil cultivou 479,6 mil hectares, enquanto a Indonésia, com seus 105 mil hectares, apresentou 4,2 vezes a produtividade brasileira. O desempenho da Indonésia e da Costa Rica é de 59,74t ha-1 e 55,54t ha-1 ${ }^{-1}$ respectivamente, e a produtividade brasileira $\left(14,14 \mathrm{t} \mathrm{ha}^{-1}\right)$ é bem abaixo da média mundial $\left(19,78 \mathrm{tha}^{-1}\right)$. A produção brasileira de banana, em 2010, foi de 69,63 bilhões de toneladas, destinadas, basicamente, ao mercado interno e apenas $3 \%$ destinado ao mercado internacional.

IDepartamento de Engenharia de Energias Renováveis (DEER), Centro de Energias Alternativas e Renováveis (CEAR), da Universidade Federal da Paraíba (UFPB), 58051-970, João Pessoa, PB, Brasil. E-mail: luiz@cear.ufpb.br. Autor para correspondência. 
A participação da produção de banana nas regiões brasileiras foi de $38,05 \%$ no Nordeste, $31,97 \%$ no Sudeste, $14,69 \%$ no Sul, $11,70 \%$ no Norte e 3,59\% no Centro-Oeste. Os quatro principais Estados produtores representam 52,12\% da produção nacional, sendo eles São Paulo $(17,69 \%)$, Bahia $(15,50 \%)$, Santa Catarina $(9,53 \%)$ e Minas Gerais (9,40\%). O Estado do Paraná ficou em $8^{\circ}$ lugar no ranking nacional, participando com $3,41 \%$ da produção brasileira (IBGE, 2012).

A produção de banana no Paraná vem crescendo nos últimos anos, ocupando a condição de terceira espécie frutífera no Estado. Alcançou, em 2009, a participação de 10,3\% no valor bruto de produção das frutícolas, atrás somente da uva e da laranja (SEAB, 2010). Entretanto, apresenta relevância econômica e social como alternativa na geração de emprego e renda nos municípios que a cultiva. O desenvolvimento de uma economia está associado às estratégias de diversificação, principalmente, em mercados pouco explorados, mas com potencial de crescimento, como a bananicultura no Paraná, conjugada à própria necessidade de conseguir economias de escala e escopo (COELHO JUNIOR et al., 2010).

De acordo com a teoria de economia industrial, em um sentido amplo, entende-se "concentração" como um processo que consiste no aumento do controle exercido pela atividade econômica e é um dos componentes mais importantes da competição entre os municípios. Existe uma relação inversa entre concentração e concorrência, sendo que, à medida que se eleva a concentração, o grau de competição entre as empresas diminui o que amplia o poder de mercado da empresa (POSSAS, 1999).

$O$ poder de mercado se configura na participação que uma determinada empresa possui no seu setor industrial. O cálculo dos índices de desigualdade e concentração são elementos empíricos necessários à análise da estrutura de mercado e evidencia a dimensão da competitividade (HAGUENAUER, 2012). Concentração sintetiza em um único indicador um conceito de múltiplas dimensões, como oferta e demanda, capacidade tecnológica, estrutura de custos, entre outros.

Contudo, não há estudos mostrando a concentração do valor bruto de produção da banana no Estado do Paraná. O objetivo deste trabalho é analisar grau de concentração do valor bruto da produção de banana no estado do Paraná, no período 1995-2010.

\section{MATERIAL E MÉTODOS}

Os dados utilizados para mensuração da concentração do valor bruto da produção (VBP) de banana no Paraná, para o período 1995-2010, foram obtidos junto a base de dados do Estado (BDEweb) do Instituto Paranaense de Desenvolvimento Econômico e Social (IPARDES), disponível em <http://www. ipardes.pr.gov.br/imp/index.php>.

Para caracterizar a evolução do VBP da banana no Paraná, foram utilizadas as mesorregiões paranaenses, segundo a classificação geográfica do IBGE, para os anos de 1995, 1998, 2001, 2004, 2007 e 2010. Para mensurar essa evolução, utilizou-se a taxa de crescimento geométrico.

A taxa de crescimento geométrico $\left(r_{g}\right)$ do valor bruto de produção da banana utiliza as variáveis referentes aos valores em dois períodos distintos no tempo. É expressa em percentual e calculada pela fórmula $r_{g}=\left(\sqrt[n]{\frac{p_{(t+n)}}{p_{(t)}}}\right)-1$, em que $P_{(t)}=$ VBP da banana no período $t ; \mathrm{p}_{(t+n)}=\mathrm{VBP}$ da banana no período $t+n$; $n=$ ao intervalo de tempo entre essas datas, medido em ano ou fração de ano.

Para calcular os índices de concentração do VBP da banana no Paraná, foram utilizadas informações em nível mesorregional, microrregional e municipal. As medidas de concentração são classificadas como parciais ou sumárias. Os índices parciais consideram parte dos municípios que atuam em certa indústria. Já os índices sumários utilizam dados de todos os municípios que atuam no mercado.

A razão de concentração representará os índices parciais. Já o índice de HirschmanHerfindal e o índice de Theil representaram bem os índices sumários. A Razão de Concentração [CR(k)] considera a participação no mercado dos $k$ (sendo $k=1,2, \ldots, n$ ) municípios e, ou, microrregiões de maiores VBP da banana Estadual. A forma algébrica da razão de concentração é $C R(k)=\sum_{i=1}^{k} s_{i}$, em que,

CR $(k)=$ Razão de concentração de $K$ maiores municípios de VBP da banana no Paraná; $S_{i}=$ Market share, em porcentagem, do município $i$ de VBP da banana no Paraná. Convencionalmente, utiliza-se o CR(4) e o CR(8) para análise de concentração. Para o cálculo da razão de concentração, as participações dos municípios foram ordenadas de forma decrescente.

$\mathrm{O}$ Índice Herfindahl-Hirschman (HHI) é uma ferramenta de análise de concentração de mercado que foi proposta de forma independente por Hirschman e por Herfindahl. O HHI mede 
a concentração utilizando os dados de todos os municípios, em dada indústria, por meio da expressão $H H I=\sum_{i=1}^{n} s_{i}^{2}$, em que $n=$ número de municípios

bananicultores; $S_{i}=$ market share, em porcentagem, do município $i$ no valor bruto da produção de banana.

O HHI evidencia os pesos relativos da participação de cada município. Ao se elevar ao quadrado o market share dos municípios, atribuise um maior peso aos que têm maior participação. O limite inferior do índice é $1 / \mathrm{n}$, situação em que todos os municípios têm o mesmo tamanho. Já o limite superior do índice é igual a 1, indicando haver uma concentração máxima, quando há uma situação de monopólio. Assim, à medida que o índice se afasta de $1 / \mathrm{n}$, maior será a concentração, ou seja, um índice $\mathrm{HHI}<0,1$ indica um mercado altamente competitivo. Um índice no intervalo $\mathrm{HHI}<0,15$ indica um mercado não concentrado. Um índice no intervalo $0,15 \leq \mathrm{HHI} \leq 0,25$ indica concentração moderada. E, um índice $\mathrm{HHI}>0,25$ indica alta concentração.

O Índice de Entropia foi originalmente formulado para se verificar o conteúdo informacional da mensagem que as firmas transmitiriam, dado o grau de surpresa que elas teriam, diante de certo evento. $\mathrm{O}$ índice, porém, pode ser aplicado à economia para medir a concentração do valor bruto da produção de banana no Paraná, ou em qualquer setor. A fórmula matemática utilizada para o cálculo da Entropia $(E)$ é $E=-\sum_{i=1}^{n} \ln \left(s_{i}\right)$, em que $n=$ número de municípios participantes do VBP da banana no Paraná; $S_{i}=$ market share do município $i$ para o VBP da banana no Paraná; ln = logarítmo neperiano. Um número maior de municípios implica um valor mais elevado da
Entropia, dependendo do quão desigual é o tamanho delas. Em situações de monopólio, o valor da Entropia é igual a zero, o que significa concentração máxima. Já o limite superior do índice é igual a $\ln (n)$, isto é, os municípios possuem parcelas iguais de mercado e concentração mínima.

\section{RESULTADOS E DISCUSSÃO}

A tabela 1 representa a evolução do Valor Bruto de Produção (VBP) da banana por meio das mesorregiões do Paraná, no período estudado. O VBP da banana paranaense teve crescimento médio de 12,92\% a.a. principiando, em 1995, com R\$16,44 milhões para R\$ 101,74 milhões, em 2010.

Muito embora o zoneamento agrícola do estado aponte que a bananicultura tem a potencialidade de abranger $60 \%$ dos municípios paranaenses, distribuídos nas mesorregiões Noroeste, Centro-Ocidental, Norte Central, Norte Pioneiro, Oeste, Sudoeste e Metropolitana de Curitiba, observa-se que a produção estadual de banana se caracteriza pela ocorrência de polos regionais (Metropolitana de Curitiba e Norte Pioneiro).

Em 1995, a região Metropolitana de Curitiba, pioneira no cultivo no Paraná, participou cerca de $80 \%$ do VBP banana paranaense e caiu a $60 \%$ do VBP da banana paranaense em 2010. Isso se deve ao aumento de participação do norte pioneiro, que saiu de $8,77 \%$ do VBP, em 1995, para 26,04\% de participação em 2010 e a contribuição oeste e noroeste no VBP da banana estadual. Apesar dessa queda da Região metropolitana de Curitiba no market share do VBP estadual, esta apresentou um crescimento de 10,94\% a.a.. A mesorregião norte pioneiro também apresenta uma boa participação na conjuntura da banana do Paraná.

Tabela 1 - Valor bruto de produção da banana no Paraná, no período de 1995 a 2010 (R\$1.000,00).

\begin{tabular}{llllll}
\hline Mesorregiões & 1995 & 1998 & 2001 & 2004 & 2007 \\
\hline Centro-Ocidental Paranaense & 69 & 100 & 279 & 408 & 291 \\
Centro-Oriental Paranaense & 33 & 24 & - & 98 & 38 \\
Centro-Sul Paranaense & 101 & 102 & 39 & 187 & 155 \\
Metropolitana de Curitiba & 12.798 & 12.969 & 14.173 & 42.714 & 55.628 \\
Noroeste Paranaense & 25 & 44 & 355 & 544 & 500 \\
Norte Central Paranaense & 713 & 687 & 5.003 & 3.151 & 3.509 \\
Norte Pioneiro Paranaense & 1.442 & 828 & 10.365 & 16.565 & 17.588 \\
Oeste Paranaense & 948 & 836 & 2.258 & 4.973 & 3.025 \\
Sudeste Paranaense & - & 1 & 11 & 7 & 234 \\
Sudoeste Paranaense & 314 & 433 & 826 & 1.760 & 22 \\
Estado do Paraná & 16.443 & 16.024 & 33.309 & 70.407 & 3.213 \\
\hline
\end{tabular}

Fonte: IBGE (2012). Elaborado pelos autores. 
No período de 1995 a 2010 , as taxas de crescimento dos VBP's da banana das mesorregiões noroeste e norte pioneiro foram de $26,66 \%$ a.a. e $21,42 \%$ a.a., respectivamente. A mesorregião sudoeste apresentou crescimento superior à média estadual de $17,26 \%$ a.a. O VBP da banana paranaense, durante o quadriênio 1995-1998, apresentou uma leve queda de $-0,86 \%$ a.a. Em 1998, a região Metropolitana de Curitiba apresentou participação mais elevada do período em estudo.

Já para no quadriênio 1998-2001, verificase um salto no VBP da banana, que passou de R\$ 16.024 milhões, em 1998, para R \$ 33.309 milhões em 2001, ajustado a um crescimento com taxa de $27,62 \%$ a.a. Essa expansão da bananicultura ocorreu devido ao excepcional desempenho da mesorregião norte pioneiro e noroeste do VBP estadual, que foram da ordem de $132,19 \%$ a.a. e $100,57 \%$ a.a., neste quadriênio, respectivamente.

Na primeira década do século XXI, 2001 a 2010, o VBP da banana Paranaense foi de R $\$ 33$ milhões para a casa de centenas de milhões de Reais, proporcionando um crescimento de $13,21 \%$ a.a., bem superior, quando comparando com o período 1995 2010. Os melhores desempenhos foram Centro-Sul $(22,03 \%$ a.a.), região Metropolitana de Curitiba (17,55\% a.a.) e Sudoeste (17,10\% a.a.).

Partindo da base de uma bananicultura tradicional que detém um baixo padrão tecnológico, os municípios do litoral pareciam ter sua hegemonia ameaçada no começo da década. Entretanto, os municípios do litoral apresentaram nesta análise taxas de crescimento da produtividade bastante superiores àquelas verificadas dos novos polos de produção, como o norte paranaense, mantendo a condição de principal região produtora.

O quadriênio 2001-2004 foi o maior incremento médio anual estadual de $28,34 \%$ a.a., em que se pode destacar a excepcional expansão do Centro-Sul (68,63\% a.a.), região Metropolitana de Curitiba (44,45\% a.a.), Oeste (30,11\% a.a.) e Sudoeste (28,68\% a.a.). Por outro lado, a Mesorregião Norte Central expôs uma queda no VBP de R \$ 5,00 milhões para $\mathrm{R} \$ 3,1$ milhões.

O quadriênio 2004-2007 ostentou um crescimento de $6,05 \%$ a.a., principalmente, devido à expansão continua da cultura na Região Metropolitana de Curitiba e Sudoeste, com taxas de 9,20\% a.a. e $22,22 \%$ a.a., respectivamente. Por sua vez, a Mesorregião Oeste teve uma progressão negativa de 15,27 a.a., fruto da expansão da cultura de grãos. Foi no quadriênio 2007-2010 que o VBP da banana no Paraná quebrou a barreira dos R\$ 100 bilhões, apresentando, neste quadriênio, taxas de $11,16 \%$ a.a.
A figura 1 mostra a razão de concentração dos VBP's da banana no Paraná em nível de microrregiões [Figura 1 a)] e municípios [Figura 1 b)], no período de 1995 a 2010. Paranaguá e Cornélio Procópio foram as microrregiões que mais representaram o $\mathrm{CR}(4)_{\text {Micro }}$ ao longo do período em análise, praticamente, primeiro e segundo no ranking Estadual.

As microrregiões Foz do Iguaçu, Francisco Beltrão, Curitiba, Apucarana, Wenceslau Braz, Capanema e Jacarezinho também contribuíram para compor o $\mathrm{CR}(4)_{\text {Micro }}$ em alguns períodos. Os municípios Guaratuba, Andirá e Morretes foram os mais representativos do $\mathrm{CR}(4)_{\text {Munic }}$ e, em alguns períodos, apontam os municípios de Guaraqueçaba, Antonina e Paranaguá.

Com base em SCHERER \& ROSS (1990), quando os quatro municípios de VBP da banana detêm mais de $40 \%$ do mercado, proporcionam estrutura oligopolista. Assim, no período estudado (1995-2010), o VBP da banana no Paraná, em nível municipal, apresenta uma estrutura de mercado oligopolista com concentração moderadamente alto a muito alto. Consequentemente, a Razão de Concentração, a nível microrregional, tende a ser ainda mais concentrada, com base nas vocações locais para o desenvolvimento da cultura.

Seguindo as orientações de BAIN (1959) para avaliar a concentração do mercado, os resultados mostraram que a razão de concentração dos quatro maiores municípios $\left[\mathrm{CR}(4)_{\text {Munic }}\right.$ ] de VBP da banana no Paraná ficou distribuída entre 46,41\% a $75,99 \%$, com uma média de $63,87 \%$ e variância de 62,17 . Indicou um grau de concentração alto (1995 e 1996), muito alto (1997) a alto (1998) e oscilando entre moderadamente alto (1999 a 2004, 2009 e 2010) a alto (2003, 2005 a 2008). Há tendência de desconcentração do mercado de alto para moderadamente alto ao longo do tempo, principalmente, a partir do início do século XXI.

Essa desconcentração se deve pelos ganhos tecnológicos de produção e manejo, aumento de produção dos municípios que não inseridos $\mathrm{CR}(4)_{\text {Munic }}$ e de diversificação da renda no meio rural. Também, nesse mesmo período, foi mensurada a concentração dos oito maiores municípios $\left[\mathrm{CR}(8)_{\text {Munic }}\right]$ de VBP da banana no Paraná, informando que esta dispersou entre $59,49 \%$ a $87,49 \%$, com uma média de $76,92 \%$ e variância de 45,76 , indicando um grau de concentração moderadamente alto, com uma queda na concentração no ano de 2001 e 2002 para moderadamente baixo e, em 1997, a concentração subiu para alto.

Ciência Rural, v.43, n.12, dez, 2013. 


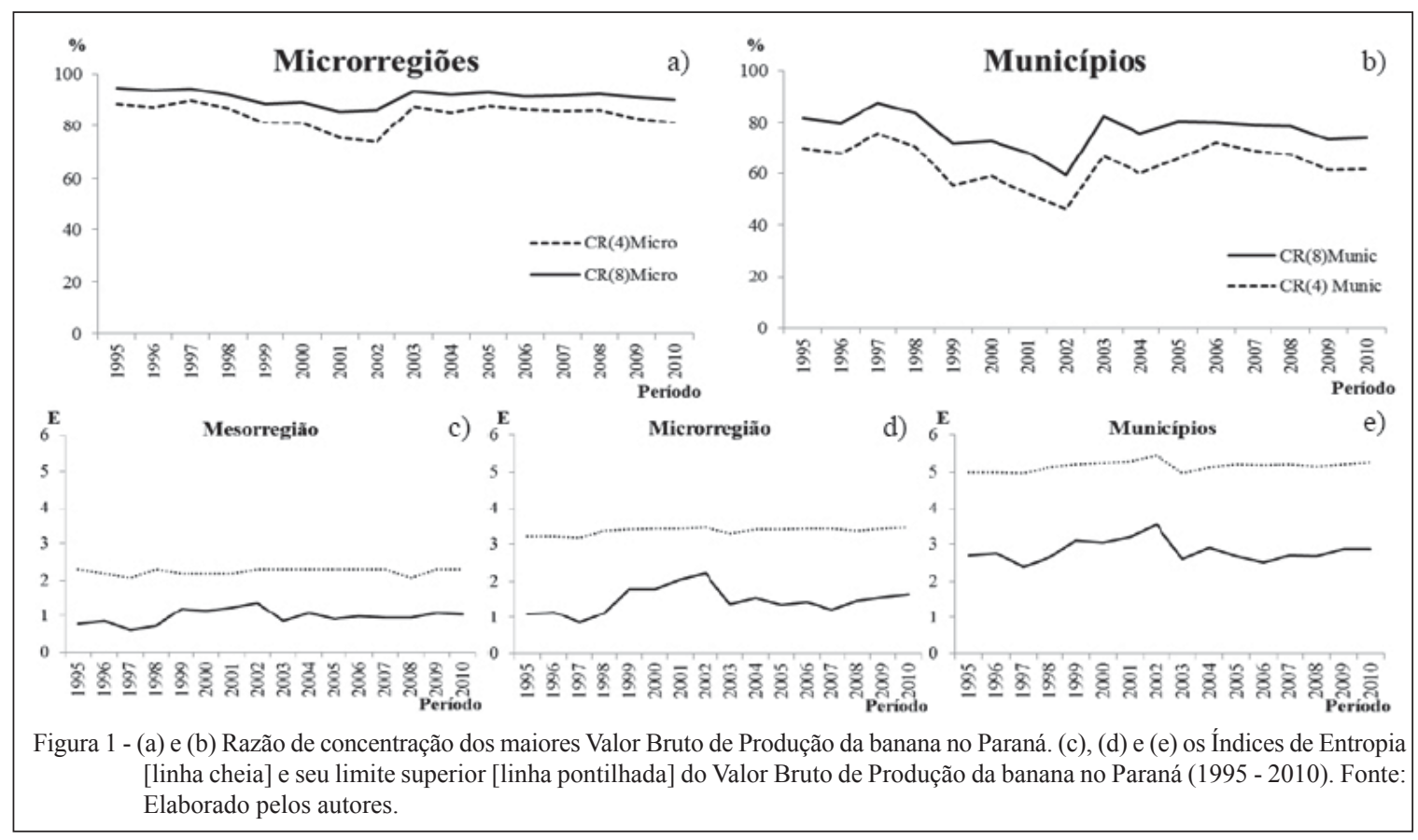

A concentração das quatro maiores microrregiões $\left[\mathrm{CR}(4)_{\text {Micro }}\right.$ ] de VBP da banana no Paraná teve amplitude de $73,83 \%$ a $90,10 \%$, com média de $84,41 \%$ e variância de 0,22 , expondo um grau de concentração muito alto, no período 1995 2010, com exceção do ano de 2002, com concentração alta. A concentração dos oito maiores municípios
[CR(8) $\left.{ }_{\text {Micro }}\right]$, distribuídos entre $85,90 \%$ a 94,85\%, média de $91,41 \%$ e variância de 0,07 , indicou grau de concentração muito alto, com exceção dos anos de 1999 a 2002, com concentração alta.

A tabela 2 representa os Índices de Herfindahl-Hirschman (HHI) do VBP da banana no Paraná por meio dos seus níveis municipais,

Tabela 2 - Índices Herfindahl-Hirschman (HHI), limite inferior do HHI (LI) do Valor Bruto de Produção da banana no Estado do Paraná (1995-2009).

\begin{tabular}{|c|c|c|c|c|c|c|c|c|c|}
\hline \multirow{2}{*}{ Anos } & \multicolumn{3}{|c|}{---------------Mesorregião----------------- } & \multicolumn{3}{|c|}{ 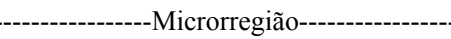 } & \multicolumn{3}{|c|}{ 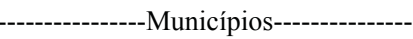 } \\
\hline & HHI & LI & $\mathrm{n}^{\mathrm{o}}$ & HHI & LI & $\mathrm{n}^{\mathrm{o}}$ & HHI & LI & $\mathrm{n}^{\mathrm{o}}$ \\
\hline 1995 & 0,6191 & 0,1111 & 10 & 0,6111 & 0,0417 & 25 & 0,1315 & 0,1256 & 148 \\
\hline 1996 & 0,5949 & 0,1250 & 9 & 0,5864 & 0,0417 & 25 & 0,1271 & 0,1212 & 149 \\
\hline 1997 & 0,7258 & 0,1429 & 8 & 0,7225 & 0,0435 & 24 & 0,1568 & 0,1509 & 145 \\
\hline 1998 & 0,6631 & 0,1111 & 10 & 0,6255 & 0,0357 & 29 & 0,1360 & 0,1308 & 169 \\
\hline 1999 & 0,3771 & 0,1250 & 9 & 0,3267 & 0,0345 & 30 & 0,1008 & 0,0959 & 183 \\
\hline 2000 & 0,3680 & 0,1250 & 9 & 0,3116 & 0,0333 & 31 & 0,1186 & 0,1139 & 190 \\
\hline 2001 & 0,3058 & 0,1250 & 9 & 0,2373 & 0,0333 & 31 & 0,1020 & 0,0973 & 195 \\
\hline 2002 & 0,2889 & 0,1111 & 10 & 0,1798 & 0,0323 & 32 & 0,0751 & 0,0710 & 230 \\
\hline 2003 & 0,5014 & 0,1111 & 10 & 0,4450 & 0,0385 & 27 & 0,1572 & 0,1513 & 144 \\
\hline 2004 & 0,4311 & 0,1111 & 10 & 0,3921 & 0,0345 & 30 & 0,1265 & 0,1213 & 168 \\
\hline 2005 & 0,5050 & 0,1111 & 10 & 0,4749 & 0,0345 & 30 & 0,1696 & 0,1650 & 181 \\
\hline 2006 & 0,4824 & 0,1111 & 10 & 0,4516 & 0,0333 & 31 & 0,2174 & 0,2130 & 180 \\
\hline 2007 & 0,4873 & 0,1111 & 10 & 0,4316 & 0,0333 & 31 & 0,1712 & 0,1667 & 184 \\
\hline 2008 & 0,4522 & 0,1429 & 8 & 0,4024 & 0,0357 & 29 & 0,1749 & 0,1700 & 171 \\
\hline 2009 & 0,4484 & 0,1111 & 10 & 0,4091 & 0,0333 & 31 & 0,1752 & 0,1706 & 182 \\
\hline 2010 & 0,4299 & 0,1111 & 10 & 0,3627 & 0,0323 & 32 & 0,1588 & 0,1544 & 192 \\
\hline
\end{tabular}

Fonte: Elaborado pelos autores.

Obs. $\mathrm{n}^{\mathbf{0}}$ é igual ao número de participantes para os diferentes níveis regionais estudados. 
microrregionais e mesorregionais. Entre 1995 a 2010, os HHI's em nível mesorregional $\left(\mathrm{HHI}_{\text {Meso }}\right)$ e microrregional $\left(\mathrm{HHI}_{\text {Micro }}\right)$ apresentaram comportamentos semelhantes ao longo do tempo, que tendeu à desconcentração de mercado.

$\mathrm{O}$ HHI municipal $\left(\mathrm{HHI}_{\text {Munic }}\right)$ apresentou comportamento distinto dos demais (HHI $\mathrm{Heso}_{\text {Me }} \mathrm{e}$ $\left.\mathrm{HHI}_{\text {Micro }}\right)$, mostrando que os municípios tendem a um mercado de concentração. A concentração inferida pelo $\mathrm{HHI}_{\text {Meso }}$ e $\mathrm{HHI}_{\text {Micro }}$ foi crescente entre 1995 a 1997, que apresentou maior índice de concentração no período estudado, proporcionado pela diminuição de Mesorregiões e Microrregiões. Observando esse mesmo período, o $\mathrm{HHI}_{\text {Munic }}$ que também se eleva, partindo de um mercado competitivo para um mercado concentrado.

Entre 1997 e 2002, para o $\mathrm{HHI}_{\text {Meso }}$ e $\mathrm{HHI}_{\text {Micro' }}$ o número de regiões aumentaram, fazendo com que concentração diminuísse, atingindo seus valores mais baixos do período em estudo. $\mathrm{O} \mathrm{HHI}_{\text {Meso }}$ permaneceu altamente concentrado, enquanto o $\mathrm{HHI}_{\text {Micro }}$ saiu de altamente concentrado para concentrado. Já o $\mathrm{HHI}_{\text {Munic }}$ se aproximou gradualmente da homogeneidade do mercado - limite inferior, induzindo à condição de concentrado para altamente competitivo.

Essa desconcentração é, principalmente, devido ao crescimento do market share das regiões e municípios intermediários. Em 2003, as mesorregiões permanecem constantes, enquanto as microrregiões caem de 32 para 27. A concentração aumenta, principalmente, devido ao crescimento abrupto do market share tanto para o $\mathrm{HHI}_{\text {Meso }}$ quanto para $\mathrm{HHI}_{\text {Micro }}$. No entanto, $\mathrm{HHI}_{\text {Munic }}$ se elevou, mas não com o mesmo incremento dos outros HHI's. De 2004 a 2010, o comportamento dos $\mathrm{HHI}_{\text {Meso }}$ e $\mathrm{HHI}_{\text {Micro }}$ são idênticos e isso indicou um alto grau de concentração, despontando em queda em 2004 e elevando em 2005 ao mesmo patamar de 2003.

A partir de 2006, o grau de concentração caiu gradativamente. $\mathrm{O}$ mesmo desempenho não acontece para $\mathrm{HHI}_{\text {Munic }}$, para o qual o grau de concentração continuou crescendo gradativamente até 2006. Em 2007, $\mathrm{HHI}_{\text {Munic }}$ apresentou uma leve desconcentração, mas permaneceu num grau de concentração estável e constante até 2010 .

As figuras 1(c), 1(d) e 1(e) representam os índices de entropia do VBP da banana no Paraná por meio dos níveis municipais $\left(\mathrm{E}_{\text {Munic }}\right)$, microrregionais $\left(\mathrm{E}_{\text {Micro }}\right)$ e mesorregionais $\left(\mathrm{E}_{\text {Meso }}\right)$, no período de 1995 a 2010. Para os três níveis, inferiu-se que o $\mathrm{E}_{\text {Munic }}$ permaneceu estacionário, enquanto o $\mathrm{E}_{\text {Micro }}$ e o $\mathrm{E}_{\text {Meso }}$ teve uma leve desconcentração. Os períodos de maior concentração para os três níveis foi o ano de 1997. De 1997 a 2002, ambos os níveis apresentam diminuição na concentração, embora seus incrementos sejam completamente distintos.

Nesse período, o $\mathrm{E}_{\text {Micro }}$ foi quem apresentou maior grau de desconcentração, aproximando mais do limite superior, devido a uma maior participação de microrregiões e uma melhor distribuição do market share. $\mathrm{O} \mathrm{E}_{\text {Meso }}$ ostentou incremento intermediário no grau de concentração e o $E_{\text {Munic }}$ proporcionou desconcentração mais gradativa nesse período. Contudo, no ano de 2002, o grau de concentração $\mathrm{E}_{\text {Meso }}$ chegou próximo ao $\mathrm{E}_{\text {Munic }}$ nesse período.

Essa desconcentração não se sustentou para as microrregiões, o $E_{\text {Micro }}$ inferiu um grau de concentração mais agressivo e que durou mais tempo entre o período de 2002 a 2007. Para os municípios, $\mathrm{E}_{\text {Munic }}$ indicou aumento de concentração gradativo, mas sua duração foi inferior ao $\mathrm{E}_{\text {Micro }}$ de 2002 a 2006 e o grau de concentração do $\mathrm{E}_{\text {Meso }}$ também aumentou, só que num ciclo menor (2002 a 2005). Após essa concentração, o $\mathrm{E}_{\text {Meso }}$ teve leve desconcentração no período de 2005 a 2010, o mesmo não aconteceu para os outros indicadores regionais. $\mathrm{E}_{\text {Munic }}$ apresentou desconcentração a partir de 2006 e $\mathrm{E}_{\text {Micro }}$ respondeu a essa desconcentração de forma mais acelerada depois de 2007.

\section{CONCLUSÃO}

Com as condições descritas neste estudo, conclui-se que: o valor da produção de banana no Paraná apresentou um crescimento médio de 12,92\% a.a. no período; os principais polos de produção de banana foram as mesorregiões Metropolitana de Curitiba e o Norte Pioneiro; a razão de concentração municipal foi moderadamente alta a muito alta e microrregional ainda mais concentrada; o índice de Herfindahl-Hirschman apresentou tendência de desconcentração para os níveis mesorregional e microrregional, enquanto o municipal apontou leve concentração; o índice de Theil mostrou tendência de concentração estacionária nos níveis microrregional e municipal e leve concentração para mesorregião; é recomendado cautela na análise dos índices sumários (HHI, E) e que a análise destes seja feita em conjunto com os índices parciais $[\mathrm{CR}(\mathrm{k})]$ para evitar conclusões errôneas. As regiões com expressiva participação no VBP da banana paranaense devem buscar estratégias comerciais para reter as vantagens competitivas conquistadas, principalmente aquelas advindas do ganho de escala. 


\section{REFERÊNCIAS}

BAIN, J. Industrial organization. New York: J. Wiley, 1959. 274 p.

COELHO JUNIOR, L.M. et al. Analysis of the Brazilian cellulose industry concentration (1998 a 2007). Cerne, Lavras, v.16, n.2, p. 209-216, abr./jun. 2010.

FAO (FOOD AND AGRICULTURE ORGANIZATION). FAO statistical databases. Disponível em: <http://www.faostat.fao. org >. Acesso em: 30 abr. 2012.

HAGUENAUER, L. Competitividade: conceitos e medidas: uma resenha da bibliografia recente com ênfase no caso brasileiro. Revista Economia Contemporânea, v.16, n.1, p.146-176, 2012.
IBGE (INSTITUTO BRASILEIRO DE GEOGRAFIA E ESTATÍSTICA). Sidra. Disponível em: <www.sidra.ibge.gov.br/ bda/pesquisas/pam/default.asp >. Acesso em: 03 jun. 2012.

POSSAS, M.L. Estruturas de mercado em oligopólio: economia e planejamento. 2.ed. São Paulo: Hucitec, 1999. 191p.

SCHERER, F.M.; ROSS, D. Industrial market structure and economic performance. 3.ed. Boston: Houghton Mifflin, 1990. 270p.

SEAB (SECRETARIA DA AGRICULTURA E ABASTECIMENTO DO PARANÁ). Valor bruto da produção agropecuária paranaense. Disponível em: <www.seab.pr.gov.br/ arquivos/File/deral/VBP.pdf>. Acesso em: 19 abr. 2012.

SOTO, M. Situación y avances tecnologicos en la producción bananera mundial. Revista Brasileira Fruticultura, v.33, n.spe., p.13-28, 2011.

Ciência Rural, v.43, n.12, dez, 2013. 